\title{
The hands that feed us
}

Transforming the food system for human and planetary health must support the livelihoods and well-being of those working in the agri-food sector.

$\mathrm{D}$ igitalization supports unparalleled opportunities for communication in the food system - facilitating food traceability, rapid product recall, product development and enhanced consumer experience. Data increasingly shapes narratives around food; and yet, big data can fail to capture the stories, often harrowing, of the countless individuals involved in bringing our food from farm to fork. Transformation of the food system depends on them, the hands that feed us.

One third of the global workforce is engaged in agriculture; although the proportion of those employed in agriculture varies widely between nations and regions. Women make up more than $40 \%$ of the agricultural workforce and produce more than half of all food grown globally, but their work in agriculture is often undervalued - with poor access to economic resources, absence of land and property rights, and their role in agriculture perceived as 'provider' rather than 'farmer'. Inequalities in the food system are deeply gendered and this is why United Nations (UN) Sustainable Development Goal (SDG) 5 , achieving gender equality and empowering all women and girls, is central to food system transformation.

In 2018, 152 million 5 to 17 year olds were defined by the International Labour Organization as child labourers and the majority, 108 million, were engaged in agriculture - removed from formal education and engaged in farm activities such as the operation of heavy machinery, heavy-load bearing and exposure to pesticides. The agriculture and food sectors are also particularly susceptible to human trafficking and modern slavery. Recently, Hilal Elver of the UN noted that half the agricultural workforce in Italy were migrants, many without documents, working excessively long hours under difficult conditions with a salary too low to cover basic needs - "left in limbo" and exploited by a sophisticated food system. SDG 8 aims to eradicate forced labour, child labour, end modern slavery and human trafficking, and is vital for building and sustaining justice in the food system.

Suicide rates among those working in agriculture and food preparation are higher than in the general population. A recent global systematic review of mental health in the agriculture sector found, in the majority of studies, that the farming community had poorer mental health than the general population. Risks identified for mental illness among farm and farm workers included pesticide exposure, climate variability, regulatory burdens, debt and commodity prices; resulting in anxiety,depression, inability to make decisions, social withdrawal, burnout and substance abuse ${ }^{1}$. The pattern continues from studies of workers in food processing, with higher prevalence of depressive symptoms and chronic occupational injury among low-paid, predominantly female workers in poultry plants. A study from Brazil lays out in graphic terms the poor conditions of these workers - intense cold, repetitive work in cramped conditions, biological risks from exposure to entrails, blood and excrement, impossibility of interaction due to intense noise, harassment and humiliation ${ }^{2}$. The speed and unceasing flow of the production line affords little or no control of work rate and is cited frequently in the literature as a significant cause of anxiety for the food processing workforce. Promoting workers' rights, safe and secure working environments and achieving decent work for all are targets of SDG 8, and should be at the fore of transforming food systems.

With advances in machine learning and $\mathrm{AI}$, the hands that feed us are set to become increasingly digitized in the future. Though big data has the potential to reduce narratives of food provenance to issues of supply chain processes - multinationals have begun to explore the capabilities of distributed ledger technology in rooting out issues of land rights, child labour and forced labour along the food supply chain. The potential of blockchain as a tool of food justice is immense.

As we focus on transformation of the food system for planetary and human health, we must not lose sight of the SDGs, all 17 of them, as they relate to those working in the food supply chain - including gender equality, elimination of forced and child labour, workers' rights and decent work for all. Addressing oppression is "not extra work for transforming the food system - it is the work"

Published online: 18 February 2020 https://doi.org/10.1038/s43016-020-0044-7

\footnotetext{
References

1. Daghagh Yazd, S., Wheeler, S. A. \& Zuo, A. Int. J. Environ. Res. Public Health 16, 4849 (2019).

2. Hutz, C. S., Zanon, C. \& Neto, H. B. Psicol. Reflex. Crit. 26, 296-304 (2013).

3. Holt-Giménez, E. Food Systems and Movements (CFF, 2015); https://go.nature.com/377QpgZ
} 